\title{
Tight junction dynamics: the role of junctional adhesion molecules (JAMs)
}

\author{
S. Garrido-Urbani • P. F. Bradfield • B. A. Imhof
}

Received: 27 November 2013 / Accepted: 16 January 2014 / Published online: 5 March 2014

(C) Springer-Verlag Berlin Heidelberg 2014

\begin{abstract}
Junctional adhesion molecules (JAMs) are a family of adhesion molecules localized at the tight junction of polarized cells and on the cell surface of leukocytes. The last 20 years of research in this field has shown that several members of the family play an important role in the regulation of cell polarity, endothelium permeability and leukocytes migration. They mediate these pleiotropic functions through a multitude of homophilic and heterophilic interactions with intrafamily and extrafamily partners. In this article, we review the current status of the JAM family and highlight their functional role in tight junction dynamics and leukocyte transmigration.
\end{abstract}

Keywords Tight junction $\cdot$ JAM $\cdot$ Polarity $\cdot$ Leukocyte migration $\cdot$ Inflammation

\section{Introduction}

Epithelial and endothelial cells can assemble into cellular sheets that form a physical barrier between different tissues. To form these barriers, the cells establish and maintain several different types of intercellular junctions. Tight junctions (TJs) are the most apical type of junction, with the physical contact point bordering as a belt on the upper lateral membrane of polarized epithelial cells whereas adherens junctions, desmosomes and gap junctions are organized in a scattered lateral distribution. At the level of the TJ, the intercellular space is

\footnotetext{
S. Garrido-Urbani $(\bowtie) \cdot$ P. F. Bradfield $\cdot$ B. A. Imhof

Department of Pathology and Immunology, CMU, University of

Geneva, Geneva, Switzerland

e-mail: sarah.garrido-urbani@unige.ch

B. A. Imhof

e-mail: beat.imhof@unige.ch
}

practically absent as the two cell membranes are in direct contact with each other and can appear fused.

Many studies have been conducted over the last 50 years that have specifically focused on the biology of cell junctions. TJs were initially visualized as a fusion point or "kissing" points between two adjacent cell membranes, thus explaining why TJs were referred to as zonula occludens (Farquhar and Palade 1963). The underlying functionality of these structures was proposed in a later study using electron microscopy where the diffusion of a tracer was observed to be restricted across endothelial barriers in the mouse brain (Reese and Karnovsky 1967). A few years later, it was confirmed that occluding TJs of parenchymal brain capillaries and the epithelial layer of choroid plexus form the structural basis of the blood-brain barrier (BBB) (Brightman and Reese 1969). The role of TJs in barrier formation was shown in studies that measured transepithelial electrical resistance (TER), which correlated directly with the number of TJ strands (Claude 1978; Claude and Goodenough 1973). In the 1980s, the new freeze-fracture technology demonstrated that the enhanced barrier functionality of the BBB may be mediated by the extended numbers of tight junctional belts in the endothelium of cerebral capillaries (Nagy et al. 1984). In these more recent studies, it has become clear that the number of TJ strands and the complexity of their ramification can vary significantly between cell types and plays a key role in dictating barrier function.

TJs form a molecular obstruction for solutes between the apical and the basolateral domains of epithelial and endothelial cells. Therefore, TJs are essential for the establishment and the maintenance of cell polarity and act in coordination with adherens junctions. However, TJs are not impermeable structures, they show a certain selectivity and specificity for ions and molecules through aqueous pores and transporters (Tsukita et al. 2001). For example, endothelial cells play a key role in regulating the inflammatory response by 
controlling permeability and leukocyte trafficking processes (Bazzoni and Dejana 2004).

Key to this function is the existence of an extensive array of intracellular signaling molecules. Cell signaling events mediated by cytoplasmic partners of TJ molecules have been shown to modulate endothelial function by regulating proliferation and differentiation processes (Guillemot et al. 2008; Tsukita et al. 2001). TJs are composed of the transmembrane proteins called occludin, the claudins and the junctional adhesion molecules (JAMs) and the cytoplasmic polarity complex molecules including ZO-1, AF-6, MUPP-1, MAGI-1, cingulin and PAR-3 (Guillemot et al. 2008; Tsukita et al. 2001). The first proteins to be characterized were occludin and the first two claudins (Furuse et al. 1998), which are part of a family consisting in 24 members (Angelow et al. 2008). In the cytoplasm, the ZO proteins, MUPP-1, cingulin, MAGI-1 and AF-6, form a dense plaque, which links the membrane proteins to the actin cytoskeleton and transmits intracellular signaling. Surprisingly, in occludin-deficient epithelia, the TJs are still present and functional, which questioned the precise role for occludin in the TJ structure. An essential role for this molecule was confirmed in occludin-deficient animals where impairment of epithelial barrier function was shown to lead to growth retardation, male sterility and gastritis (Saitou et al. 2000). Meanwhile, claudins were shown to be essential molecules for forming a functional barrier (Angelow et al. 2008). Indeed, exogenous expression of claudins in non-polarized cells induced the neoformation of TJs and mediated tight cellto-cell adhesion (Angelow et al. 2008; Furuse and Tsukita 2006; Van Itallie and Anderson 2006). The different claudins have a tissue specific distribution and the specificity of the TJ barrier can be attributed to the type of Claudins found at the junctions (Furuse and Tsukita 2006).

The JAMs are a family of transmembrane receptors localized adjacent to TJs and can form homophilic and heterophilic interactions at the adhesion contact. In contrast to Claudins, transfection of JAMs into fibroblasts did not induce TJ strand formation (Itoh et al. 2001). However, in endothelial cells, they interact with polarity complex proteins through their PDZ binding domains and are thought to regulate cell polarity and leukocytes migration (Liang et al. 2000; Liu et al. 2000). In this review, we will discuss the current knowledge about the roles of JAM proteins in the regulation of TJ dynamics.

\section{The JAM family: structure and interaction}

The JAM family belongs to the immunoglobulin super family (Williams and Barclay 1988) and is composed of seven members; three classical JAMs (JAM-A, B, C) and four related proteins (JAM-4, JAM-L, CAR, ESAM) (Fig. 1). JAMs are type I transmembrane glycoproteins, composed of two immunoglobulin-like domains, one transmembrane domain and one cytoplasmic tail of variable length containing a PDZ domain (post-synaptic density protein (PSD95)), Drosophila disc large tumor suppressor (Dlg1) and zonula occludens protein (ZO-1) binding motif. The Ig-like domains are of $\mathrm{V}$ type and $\mathrm{C} 2$ type for JAM-B and JAM-C (Aurrand-Lions et al. 2001b). The V domain contains a J-like sequence and the $\mathrm{C} 2$ type domain contains an extra disulfide bridge between cysteines. Concerning JAM-A, the nature of the Ig domain was initially described to contain $2 \mathrm{~V}$-type domains, then proposed to have two $\mathrm{C} 2$ domains and finally to have as JAM-B and -C, one V-type and one C2-type domain (Aurrand-Lions et al. 2001b). Interestingly, the JAMs have significant homology with the cortical thymocyte markers for the Xenopus (CTX) family, indicating that possible $\mathrm{V}-\mathrm{C} 2$ domain ancestors of $\mathrm{MHC}$ or T-cell receptors (TCR) had evolved through gene duplication of ancestral CTX family precursor genes (Chretien et al. 1998; Du Pasquier et al. 1999). The three classical JAMs share 32 $38 \%$ sequence identity (Aurrand-Lions et al. 2000) while they share only $14-18 \%$ with the other related non-classical family members JAM-4, JAM-L, CAR or ESAM. The non-classical JAMs differ from the classical JAMs mainly by their cytoplasmic tail. Indeed JAM-A, -B and $-\mathrm{C}$ have relatively conserved cytoplasmic sequences containing a type II PDZ binding motif at the cytoplasmic C-terminus (Bradfield et al. 2007a). This PDZ binding motif can interact with various intracellular scaffold proteins and forms polarity complexes (Ebnet et al. 2003; Mandell and Parkos 2005). The non-classical JAMs have a longer cytoplasmic tail at the $\mathrm{C}$-terminal part containing a type I PDZ binding motif. The molecules JAM-A and $-\mathrm{C}$ can be processed by metalloproteinase such as ADAM-10 or ADAM17 , leading to shedding from endothelial cell surfaces and release as a soluble factor (Koenen et al. 2009; Rabquer et al. 2010; Salifu et al. 2007). Soluble JAMs may function as adhesion inhibitors or induce chemotactic signals for endothelial cells (Rabquer et al. 2010). This process has not been shown for JAM-B and still remains an area of investigation.

JAMs can also form homophilic and heterophilic interactions in trans- and cis-configurations (Fig. 1 and Table1). JAM-A is able to interact heterophilically with the leukocyte integrin CD11a/CD18 (LFA-1) (Ostermann et al. 2002) and the endothelial integrin $\alpha v \beta 3$ (Naik et al. 2003) and is the receptor of the reovirus attachment protein $\sigma-1$ (Barton et al. 2001). JAM-B can form heterophilic interactions with JAM-C, which are of higher affinity than homophilic interactions and with the leukocyte integrin $\alpha 4 \beta 1$ (VLA-4, CD $49 \mathrm{~d} / \mathrm{CD} 29$ ) (Arrate et al. 2001; Cunningham et al. 2002). JAM-C has even more possible partners and has been shown to bind to the leukocyte integrins $\alpha \mathrm{M} \beta 2, \alpha \mathrm{X} \beta 2, \alpha \mathrm{V} \beta 3$ and CAR (Lamagna et al. 2005; Li et al. 2009; Mirza et al. 2006; Santoso et al. 2002).

The non-classical family members can also form multiple interactions. The molecule JAM-L is able to bind to nonactivated $\alpha 4 \beta 1$ integrin and CAR (Luissint et al. 2008; Zen et al. 2005). CAR is able to bind to JAM-C and JAM-L (Zen 


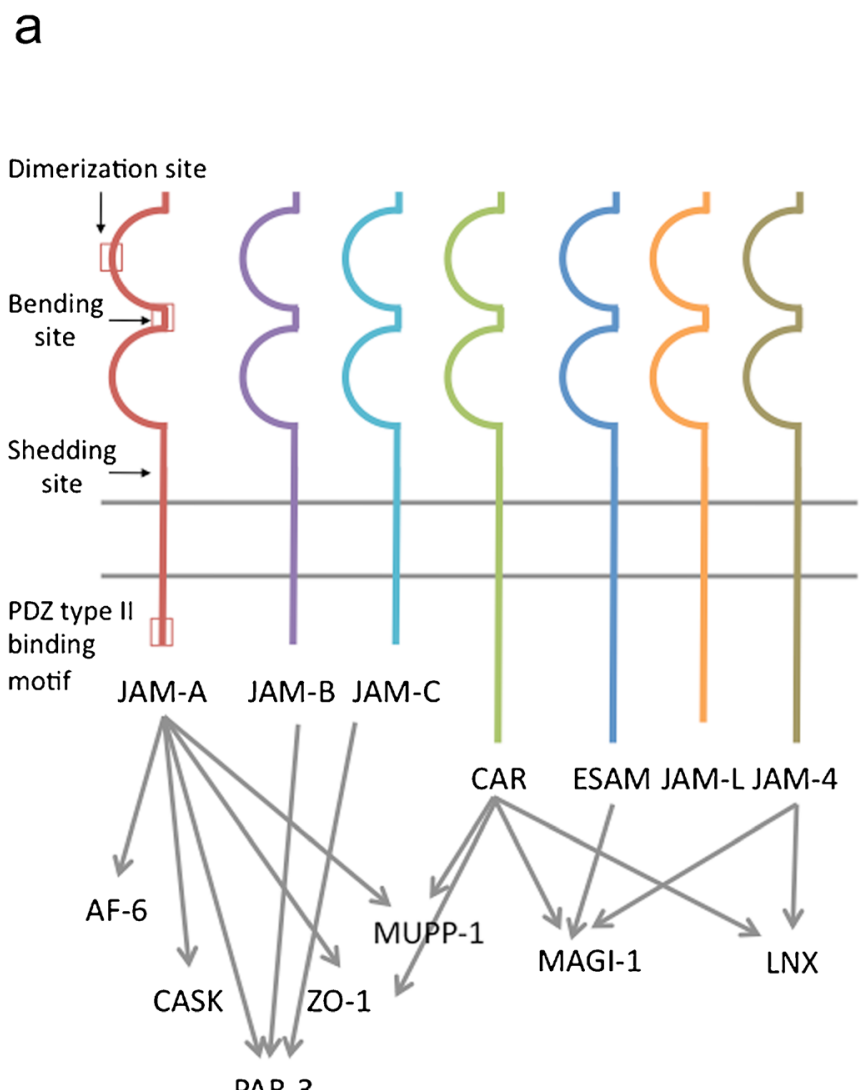

PAR-3

Fig. 1 JAM family and interactions. a. The JAM family is composed of 7 members with structural homology; two extracellular Ig-like domains, a transmembrane portion and a cytoplasmic tail. In the cytoplasmic portion, classical JAMs (A, B and C) contain a type II PDZ binding motif. Members of the non-classical JAM family (CAR, ESAM and JAM-4)

et al. 2005; Mirza et al. 2006). Concerning JAM-4 and ESAM, no heterophilic interaction has so far been described.

The protein structure for JAM-A has been devised using Xray crystallography studies. In these studies, it was shown that a three amino acid sequence (Val-Leu-Val) in the linker of the two immunoglobulin-like domains allows the distal Ig-like domains to bend and another three amino acid sequence (Arg-Leu-Glu) in the V type Ig-like domain to bind and dimerize (Kostrewa et al. 2001; Prota et al. 2003). A dimer of JAM-A at the surface of a cell will be able to interact in trans with another JAM-A dimer expressed by the adjacent cell and thus form a tetramer. At the apical cell border, the successive JAMs tetramer could form a kind of zipper structure surrounding the cell (Kostrewa et al. 2001). The same type of dimerization motif is found in JAM-B (Arg-Leu-Glu) and JAM-C (Arg-Ile-Glu) suggesting that they can form dimers in the same way as JAM-A.

The cytoplasmic portion of the JAMs can mediate proteinprotein interaction through their PDZ binding motif. The motif Phe-Leu-Val of JAM-A interacts with proteins containing type II PDZ such as ZO-1, AF-6, CASK, PAR-3 and MUPP-1 (Ebnet et al. 2000; Hamazaki et al. 2002; Itoh et al. 2001; Martinez-Estrada et al. 2001). The other JAMs also

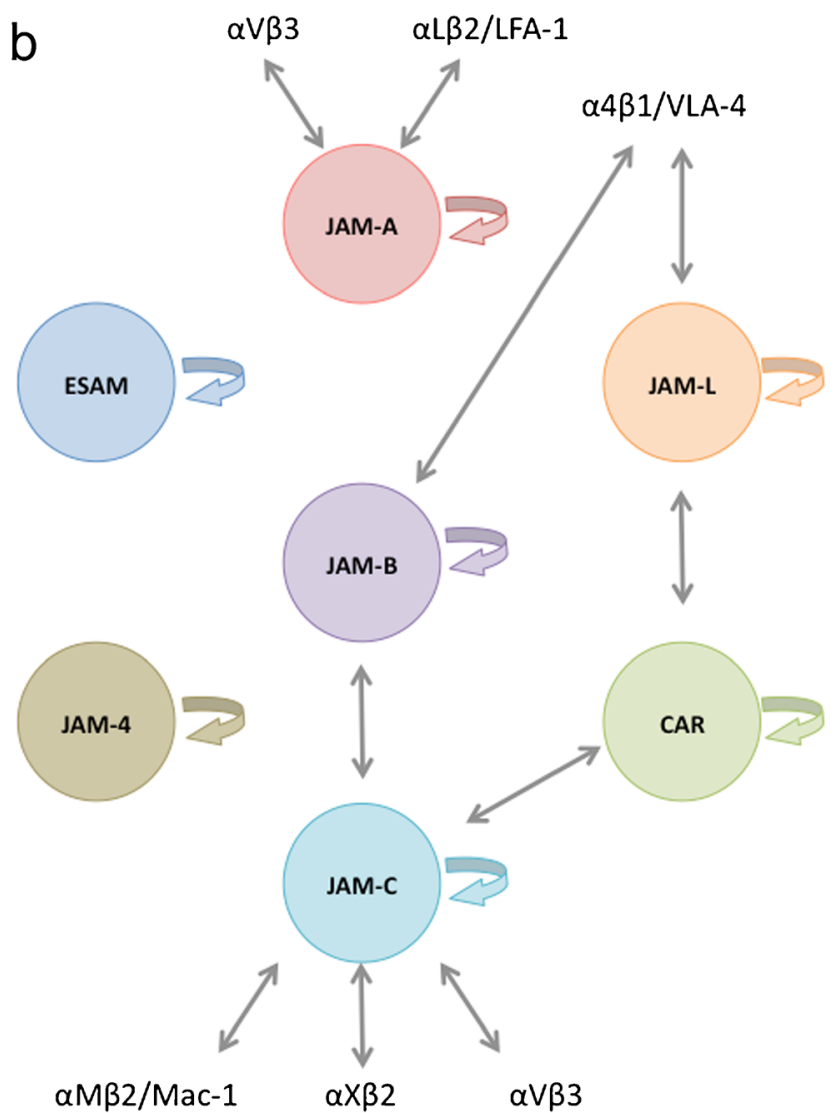

contain a type I PDZ binding motif. Both motifs can bind multiple intracellular partners (AF-6, MUPP-1, ZO-1, PAR-3, MAGI-1, LNX and CASK). b. JAMs can form homophilic interactions via their intracellular domains and can also form cis- or trans-interactions with other JAM family members or integrins

contain a PDZ binding motif of type II (JAM-B and -C) or a type I (CAR, ESAM, JAM-4). So far, the bindings of the following PDZ proteins have been identified: JAM-B and $-\mathrm{C}$ bind PAR-3 (Ebnet et al. 2003), CAR binds LNX2, ZO-1, MUPP-1 and MAGI-1 (Cohen et al. 2001; Coyne et al. 2004; Excoffon et al. 2004; Sollerbrant et al. 2003), JAM-4 binds MAGI-1 and LNX1 (Hirabayashi et al. 2003; Kansaku et al. 2006) and ESAM bind to the MAGI-1 protein (Wegmann et al. 2004). The molecule JAM-L is the only JAM family member that does not contain a PDZ binding motif and as a consequence is thought not to bind to any PDZ protein.

Through this extensive array of extracellular and intracellular interactions, it is thought that JAMs can participate in a diverse array of cell functions such as cell polarity, permeability and leukocyte migration. We will discuss some of these functions later in this review.

\section{Identification and expression pattern of JAMs (Table 2)}

The first member of the JAM family to be discovered was JAM-A (Martin-Padura et al. 1998). It was identified in a 


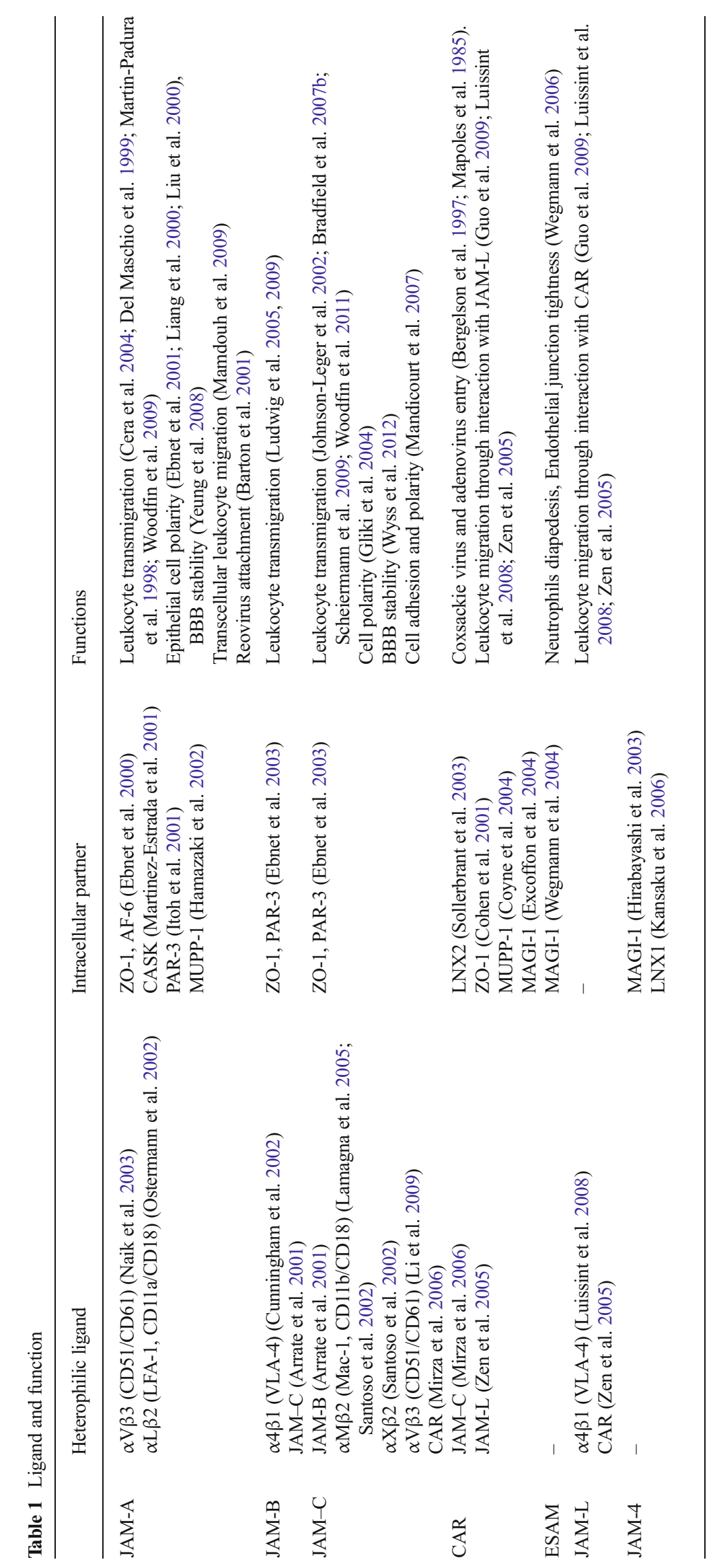


Table 2 Expression of JAMs

\begin{tabular}{|c|c|c|}
\hline & Cell expression & Tissue expression \\
\hline JAM-A & $\begin{array}{l}\text { Endothelial, epithelial cells, leukocytes and platelets } \\
\text { (Martin-Padura et al. 1998; Sobocka et al. 2000) }\end{array}$ & $\begin{array}{l}\text { Brain, liver, kidney, pancreas, heart, lymph node, intestine, } \\
\text { lung, placenta, skin, cornea (Martin-Padura et al. 1998) }\end{array}$ \\
\hline JAM-B & $\begin{array}{l}\text { Vascular and lymphatic endothelial cells (Aurrand-Lions } \\
\text { et al. 2001a; Cunningham et al. 2000; Palmeri et al. 2000) }\end{array}$ & $\begin{array}{l}\text { Brain, lymph node (HEV), skin, placenta, testis, heart, lung } \\
\text { (Aurrand-Lions et al. 2001a; Palmeri et al. 2000) }\end{array}$ \\
\hline JAM-C & $\begin{array}{l}\text { Vascular and lymphatic endothelial cells, platelets } \\
\text { and leukocytes (human) (Arrate et al. 2001) }\end{array}$ & $\begin{array}{l}\text { Brain, lymph node (HEV), skin, cornea, placenta, testis, heart, } \\
\text { lung, smooth muscle, uterus (Arrate et al. 2001) }\end{array}$ \\
\hline CAR & $\begin{array}{l}\text { Endothelial, epithelial cells, cardiomyocytes } \\
\text { (Cohen et al. 2001) (Noutsias et al. 2001) }\end{array}$ & $\begin{array}{l}\text { Cornea, skin, brain, prostate, testis, pancreas (Fechner et al. } \\
\text { 1999; Mirza et al. 2006; Tomko et al. 2000) }\end{array}$ \\
\hline ESAM & $\begin{array}{l}\text { Endothelial cells (Hirata et al. 2001; Wegmann et al. 2004) } \\
\text { platelets (Stalker et al. 2009) }\end{array}$ & Lung, heart, skin, kidney, embryos (Hirata et al. 2001) \\
\hline JAM-L & $\begin{array}{l}\text { Leukocytes (Guo et al. 2009; Luissint et al. 2008; } \\
\text { Moog-Lutz et al. 2003) }\end{array}$ & Hematopoietic tissue (Guo et al. 2009; Luissint et al. 2008) \\
\hline JAM-4 & $\begin{array}{l}\text { Epithelial cells, germ cells (Hirabayashi et al. 2003) } \\
\text { (Nagamatsu et al. 2006) }\end{array}$ & $\begin{array}{l}\text { Liver, stomach, intestine, skeletal muscle, lung } \\
\text { (Hirabayashi et al. 2003) }\end{array}$ \\
\hline
\end{tabular}

mouse endothelioma cell line as a surface antigen recognized by the antibody BV11 and characterized by expression at the TJs of endothelial and epithelial cells (Martin-Padura et al. 1998). In a separate study, this protein had already been characterized as a platelet receptor molecule recognized by the antibody F11 (F11R) (Sobocka et al. 2000). Soon after, two other JAMs were identified in endothelial cells, JAM-B (VE-JAM, human JAM2) and JAM-C (human JAM3 or mouse JAM2) (Arrate et al. 2001; Aurrand-Lions et al. 2001a; Cunningham et al. 2000; Palmeri et al. 2000). In order to standardize the nomenclature, the laboratories working on JAMs agreed with the designated terms JAM-A, -B and -C in 2002 and this was published by William A. Muller in 2003 (Muller 2003).

When transfected into polarized epithelial and endothelial cells, classical JAMs are found in the region of TJs. However, we found that they localized to distinct sub-compartments of the junction. Specifically, JAM-C was found to colocalize with ZO-1 at the TJs in MDCK cells, whereas JAM-A co-localized only partially with ZO-1 and JAM-B appeared to be more diffuse at the lateral membrane (Aurrand-Lions et al. 2001b). Furthermore, the heterogeneous expression pattern of the JAM family members in different organs reflects the heterogeneity of intercellular junctions and potential tissue-specific functions. JAM-A, for example, is highly enriched on the blood-brain barrier (BBB), where the TJs are known to have a lower permeability (Aurrand-Lions et al. 2001b). Conversely, high endothelial venules (HEV) and lymphatic endothelial cells, which can support constitutive trafficking of leukocytes, have high expression levels of JAM-B and -C but low levels of JAM-A (Aurrand-Lions et al. 2001b) (Table 2).

The non-classical JAM family member ESAM was identified in a hybridization screen of genes expressed by human umbilical vein endothelial (HUVEC) cells under migratory conditions (Hirata et al. 2001). In this study, the authors characterized the homology of the structure of ESAM and other JAM family members. Northern blot and in situ hybridization revealed that ESAM expression is restricted to endothelium, whereas JAM-A is expressed on endothelial and epithelial cells. In murine tissue, ESAM is preferentially expressed in highly vascularized tissues such as the heart and lung (Hirata et al. 2001). In mouse embryos, ESAM expression is observed in blood vessels at an early stage of development (E8.5-9.5). Another study confirmed the endothelial specificity of ESAM expression and colocalization at the TJ with ZO-1, occludin and claudins (Nasdala et al. 2002). In 2009, Stalker et al. (2009) identified ESAM expression on the surface of platelets confirming a broader expression profile for this molecule (Table 2).

The non-classical JAM family member CAR was originally characterized as a receptor for the coxsackie virus and adenoviruses (Bergelson et al. 1997; Mapoles et al. 1985). It was only in later studies that it was identified as a TJ component colocalizing with ZO-1 in epithelial cells (Cohen et al. 2001). The expression profile for this molecule is not restricted to polarized cells, as it is also expressed by myocardial cells (Noutsias et al. 2001). Human, mouse and rat CAR mRNA were detected mainly in the heart, brain, pancreas, kidney and liver (Fechner et al. 1999) and in rat the protein was also detected in epithelial cells in liver, intestines, brain, lung and kidney (Tomko et al. 2000).

The non-classical JAM family member, JAM-4, was identified in a screen searching for integral membrane proteins that interacted with MAGI-1 in a yeast two-hybrid assay using PDZ domains of human MAGI-1 as a probe (Hirabayashi et al. 2003). JAM-4 is expressed in liver, kidney, stomach, intestine and skeletal muscle with lower levels observed in lung. Furthermore, immunofluorescence studies have confirmed that JAM-4 is localized at TJ in various epithelial cell populations and colocalized with ZO-1 and MAGI-1 (Hirabayashi et al. 2003). 
As mentioned, the structure of JAM-L is different from the other JAM family members, as it does not contain a PDZ binding motif and is not expressed by endothelial or epithelial cells. It was identified by screening for retinoic acid-induced gene expression in leukemia promyelocytes (Moog-Lutz et al. 2003). JAM-L expression is found in mature hematopoietic cells and localized at cell-cell contacts with vascular endothelium (Moog-Lutz et al. 2003). Another study confirmed that JAM-L expression is restricted to the leukocyte subpopulations neutrophils, monocytes and memory T-cells (Luissint et al. 2008) (Table 2).

\section{JAMs in endothelial barrier permeability}

Cell polarity

JAMs are associated with several cytoplasmic polarity proteins indicating a role in the formation of cell junctions and cell polarity (Table 1). As discussed, most of these cytoplasmic partners contain a PDZ binding motif that can interact with the C-terminal part of JAMs. For example classical JAMs all interact with ZO-1, which also associates with the two other types of junctional molecules, occludin and the claudins (Mitic and Anderson 1998; Tsukita et al. 2001). This is of particular functional relevance as ZO-1 can also interact with actin (Fanning et al. 1998). It is thought that ZO-1 may recruit JAMs and retain them in junctions by protein stabilization.

Another important cytoplasmic partner of JAMs is AF-6 (Afadin) (Ebnet et al. 2000). Interaction between JAMs and AF-6 may be important during the early stages of junction formation, as the two molecules colocalize in early nascent spot-like junctions (Asakura et al. 1999; Ebnet et al. 2001). Further studies have shown that AF-6 recruits JAM-A to junctions, as microinjection of JAM-A into epithelial cells resulted in localization of JAM-A only at sites where AF-6 is present (Ebnet et al. 2000). The same type of experiments revealed that the presence of ZO-1 at cell-cell contacts was not sufficient to recruit JAM-A (Ebnet et al. 2000; Fukuhara et al. 2002).

JAM-A is also able to interact with PAR-3 in a PDZdependent manner. This was demonstrated by an ectopic expression model, where induced expression of JAM-A led to recruitment of PAR-3 to cell-cell contacts (Ebnet et al. 2001; Itoh et al. 2001). The molecule PAR-3 can form molecular complexes with atypical protein kinase $\mathrm{C}(\mathrm{aPKC})$ and PAR-6, which are thought to participate in cell polarization (Suzuki and Ohno 2006). Indeed, the overexpression of mutated polarity complex proteins in cells during the course of cell polarization led to the delocalization of $\mathrm{TJ}$ molecules and a disruption in endothelial function (Gao et al. 2002; NagaiTamai et al. 2002; Suzuki et al. 2001; Yamanaka et al. 2001). Therefore, JAM-A may play a critical role in maintaining cell polarization through anchoring the PAR-3-PAR6-aPKC complex at the cellular junction.

Polarization of immature junctions starts with the formation of adherens junctions (Mitic and Anderson 1998). In epithelial cells, it starts with nascent spots of contact between lamellipodia of adjacent cells containing E-cadherin, ZO-1 and JAM-A (Ebnet et al. 2001; Suzuki et al. 2002). JAM-A then, through the activation of cdc 42 and/or Rac1, recruits the polarity complex to the junction (PAR-3-PAR6-aPKC) (Yamanaka et al. 2001) (Fig. 2).

As discussed, blocking JAM-A antibodies can increase transendothelial or transepithelial permeability through disruption of JAM-A distribution at the TJ. However, some junctional integrity is maintained as it does not interfere with E-cadherin and ZO-1 recruitment to the contact sites (Liang et al. 2000; Liu et al. 2000). A disruption in junction formation is also observed when blocking the PAR-3-PAR6-aPKC complex where only immature adherens junctions can be formed. Similar to JAM-A, JAM-B and $-\mathrm{C}$ can also associate with PAR-3 and ZO-1 in a PDZ-domain-dependent manner (Ebnet et al. 2003). Neither JAM-B nor $-\mathrm{C}$ has been identified in epithelial cells suggesting that the potential existence of a JAMB/C-PAR3 complex may be restricted to endothelial cells (Ebnet et al. 2003). However, JAM-C was shown to be essential for spermatid polarity as it participates in the recruitment of polarity proteins such as PAR6, cdc42, PKC $\lambda$ and PATJ (Gliki et al. 2004). Interestingly, PAR-3 is highly specific for the classical JAMs, as ESAM and CAR do not interact with this polarity complex factor, nor do they with other components of TJs such as occludin and the claudins (Ebnet et al. 2003; Ebnet et al. 2001). Clustering of JAM-A at TJs was also responsible for recruitment of molecules involved in cell polarity formation such as PAR-3, ZO-1, ZO2, PDZ-GEF1 and GTPase Rap2c (Monteiro et al. 2013).

\section{Barrier properties and inflammation}

JAM-A also regulates tight epithelial morphology through the modulation of integrin $\beta 1$ by the small GTPase molecule Rap1 (Mandell et al. 2005). In this in vitro study, JAM-A knockdown by siRNA increased epithelial cell permeability. A similar observation was made with the expression of a mutant JAM-A lacking the homodimerization domain, suggesting that JAM-A functions on epithelial cell morphology and TJs only as a homodimer (Mandell et al. 2005). Recently, using epithelial or fibroblast cells transfected with JAM-A or $\mathrm{C}$ mutant, it was shown that serine phosphorylation brings JAM-A and -C into TJs and as a result reduces permeability of the cell layer (Iden et al. 2012; Mandicourt et al. 2007). At least for JAM-A, it can be concluded that phosphorylation was due to the activity and colocalization of aPKC at Serine 285, as a knockdown of this enzyme by siRNA reversed the effect of JAM-A localization in TJs and increased cell permeability. 
Early contact

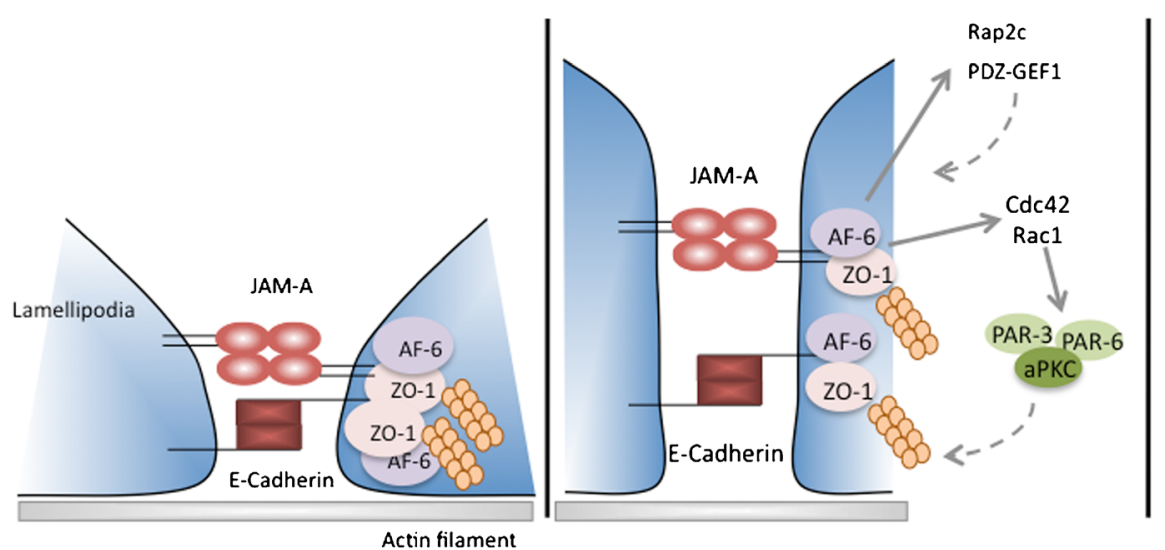

Mature junctions

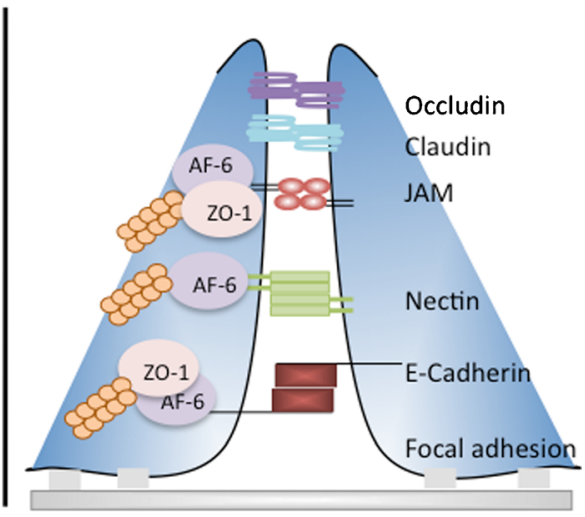

Fig. 2 Role of JAMs in cell polarization. JAM-A is known to be present in the early contact points between epithelial cells, along with E-cadherin. It is stabilized at the junction being formed by interacting with ZO-1 and AF-6, which links JAM-A to the actin cytoskeleton. To form a mature junction, the polarity complex PAR-3/PAR-6/aPKC has to be recruited.

In line with this finding, increased permeability of the gut epithelial layers was observed in a colitis model with JAM-Adeficient mice (Khounlotham et al. 2012). Furthermore, in corneal endothelium, JAM-A, -C and CAR are expressed but only JAM-A is localized at the TJ and colocalized with ZO-1 and AF-6. In a calcium depletion and recovery assay, an anti-JAM-A antibody was able to induce corneal swelling due to impaired barrier function. Thus, this study has shown an essential role for JAM-A in the functionality of the corneal endothelial barrier (Mandell et al. 2006).

Tissue or systemic inflammation induces an increased permeability of blood vessels and epithelium allowing leukocytes to migrate to the site of inflammation (Johnson-Leger and Imhof 2003). As JAMs are important regulators of epithelial and endothelial cell polarity, it is clear they can play a pivotal role in the inflammatory process. As discussed previously, an inflammatory stimulus can alter the subcellular localization of JAMs and affect tissue permeability. For example, in vitro stimulation of endothelial cells by TNF- $\alpha /$ IFN- $\gamma$ or FGF2 has been shown to induce JAM-A redistribution to the luminal side (Fig. 3) (Naik et al. 2003; Ostermann et al. 2002; Ozaki et al. 1999). JAM-C is also partially redistributed to the luminal side of endothelial cells upon oxLDL stimulation (Keiper et al. 2005) (Fig. 3). As already mentioned, JAM-Adeficient mice exhibit a defect in permeability on the intestinal lining. Under steady state conditions, the barrier shows an almost normal morphology but under inflammatory conditions, infiltration of PMN and protective lymphocytes can massively increase due to a reduced barrier function (Khounlotham et al. 2012; Laukoetter et al. 2007). Although these immune cells exert a protective function against infection, the clinical score of JAM-A-deficient mice is worse while the mucosa presents less injury and more proliferation (Khounlotham et al. 2012; Laukoetter et al. 2007).
JAM-A participates through the activation of cdc42 and Rac1. JAM-A also contributes to PDZ-GEF1 and Rap2c recruitment to the junction. In the later stage of junction formation and stabilization, the TJ molecules occludin and the claudins are recruited to stabilize and form mature cellcell junctions

In quiescent microvascular endothelial cells, JAM-C is mostly localized in the cytoplasm and is recruited to the junction upon VEGF stimulation. Under these conditions, JAM-C can regulate paracellular permeability through modulation of actomyosin-dependant contractility and VEcadherin-mediated cell-cell contact (Lamagna et al. 2005; Orlova et al. 2006). Vascular permeability is increased in thrombin-stimulated endothelial cells that overexpress JAM$\mathrm{C}$ and this might be due to coupling of JAM-C and $\beta 3$ integrins ( $\mathrm{Li}$ et al. 2009).

\section{Blood-brain barrier (BBB)}

The BBB plays an essential role in maintaining the homeostasis of the central nervous system (CNS). The barrier properties are maintained by the TJs and are characterized by very low rates of vesicle transport and a marked reduction in permeability (Engelhardt and Ransohoff 2012). Interestingly, brain capillaries in the early embryo are permeable to small molecules that cannot normally enter the adult brain. However, the BBB starts to develop an enhanced barrier function at around E13-E15 that is not completed until after birth (Wolburg and Lippoldt 2002). Several studies have shown a role for astrocytes in the establishment of the BBB that requires direct contact with the blood vessels (Tao-Cheng et al. 1987) or by secretion of soluble factors in close proximity to the vessel (Arthur et al. 1987; Wolburg et al. 1994). Whilst this micro-environmental niche maintained by astrocytes seems to be necessary to induce and maintain the BBB, other factors are also required to sustain the functionality of this structure (Rubin et al. 1991; Wolburg et al. 1994).

A breakdown in the BBB function can lead to serious damage within the CNS and a perturbation in brain function. Several diseases can lead to BBB damage through partial 


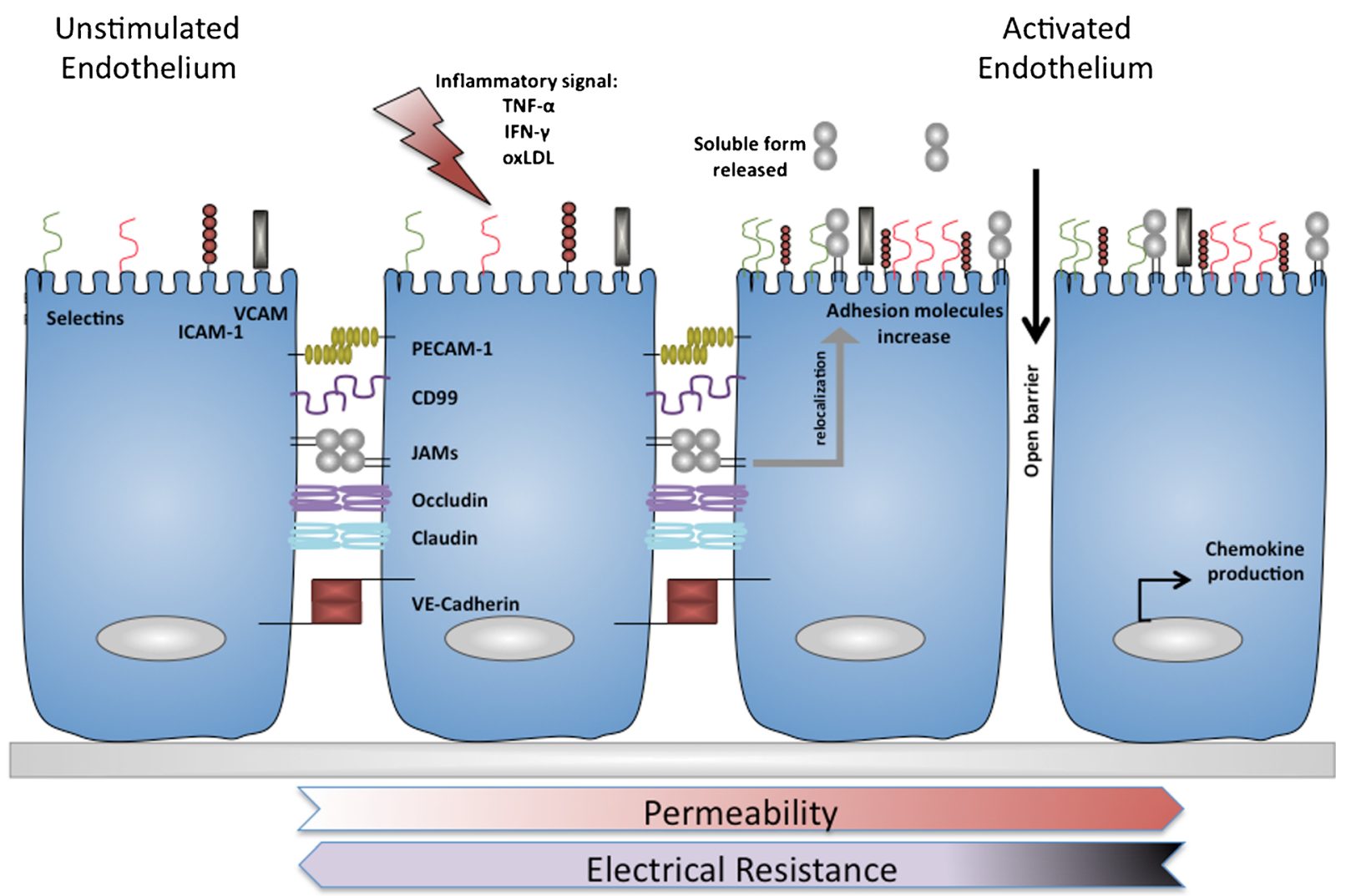

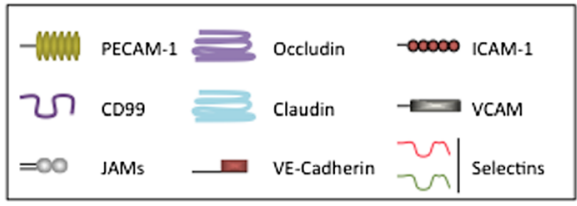

Fig. 3 JAMs regulation upon inflammatory condition. In resting endothelium, JAMs are localized at the lateral membrane in the junctional zone. Upon inflammatory stimuli with TNF- $\alpha$, IFN- $\gamma$, or OxLDL, JAMs are relocalized onto the luminal surface of the endothelial membrane

impairment or total breakdown, such as the development of tumors, stroke, multiple sclerosis, hypertension and encephalitis (Wong et al. 2013).

We mentioned the BBB here, since JAM-A, - B and -C are often localized and function at the intercellular junctions of BBB capillaries (Aurrand-Lions et al. 2001b; Martin-Padura et al. 1998; Padden et al. 2007; Vorbrodt and Dobrogowska 2004). Interestingly, a homozygotic JAM-C mutation was recently found in a consanguineous family in the United Arab Emirates that has provided an insight into the role of this molecule in humans. Some members of this family develop an autosomal-recessive syndrome leading to brain hemorrhage, subependymal calcification and cataracts (Mochida et al. 2010). In this study, they mapped the disease locus on the chromosome 11q25. Further sequence analysis of genes revealed a mutation in the intron 5 of JAM3. RT-PCR analysis of patient cells confirmed abnormal splicing, which results in an early termination of translation. This suggests an important role for JAM-C in maintaining the integrity of the where they can interact with circulating leukocytes or be processed into soluble forms by metalloproteinases. This relocalization of JAM-A increases endothelium permeability and is characterized by a decrease in electrical resistance

BBB (Mochida et al. 2010). Moreover, a study using JAM-Cdeficient mice revealed that mice backcrossed onto a C57BL6 background develop hydrocephalus characterized by enlarged ventricles and disrupted brain fluid circulation (Wyss et al. 2012).

Recently, JAM-A has been implicated in regulating leukocyte trafficking across the BBB in HIV infection models (Williams et al. 2013). This study demonstrated that upon HIV infection, CD14+CD16+ monocyte transmigration across the BBB is facilitated by increased expression of JAM-A, ALCAM, CD99 and CD31. In addition, this study confirmed that antibodies against JAM-A reduced the number of transmigrating monocytes irrespective of HIV infection status, indicating a broader role for this molecule in leukocyte trafficking (Williams et al. 2013). Furthermore, in a model of rat cortical cold-injury, JAM-A expression was lost at the lesion site $12 \mathrm{~h}$ after injury, while 2 days later the level of expression was back to normal. This loss of expression was concomitant to the BBB breakdown and demonstrates an 
essential role for JAM-A in supporting BBB integrity (Yeung et al. 2008).

\section{JAMs in leukocytes transmigration}

Leukocyte trafficking across an epithelial or endothelial barrier is an essential process in inflammation and the immunosurveillance. This process involves several distinct steps that include rolling on the luminal endothelial layer, which is followed by firm adhesion and diapedesis (Garrido-Urbani et al. 2008). The last step can use a paracellular route along adjoining endothelial cell-cell contacts or by transcytosis, where the leukocytes pass through the body of endothelial cells by forming a channel (Fig. 4). The process of transcytosis appears to be a minor route of access and has been mostly observed in vitro with neutrophils and in brain vessels in vivo (Muller 2011). An inflammatory stimulus can lead to the rapid redistribution of JAMs on endothelial and epithelial cells, which has important implications in leukocyte transmigration.
In the following part of this review, we will discuss the role of each JAM in the process of transmigration, with a particular focus on the endothelium (Fig. 4).

\section{JAM-A}

The laboratory of Elisabetha Dejana, which discovered JAMA through its interaction with the antibody BV11, has studied the role of this molecule in leukocytes transmigration. In an air-pouch model, they observed that the BV11 antibody inhibited recruitment of leukocytes to the site of inflammation (Martin-Padura et al. 1998). In vitro, they have also shown that the antibody inhibited monocyte transmigration in a static migration assay (Martin-Padura et al. 1998). This antibody specifically recognized JAM-A dimers but not monomers, indicating that a dimeric form of JAM-A is required for transmigration (Bazzoni et al. 2000). Moreover, intravenous injection of the BV11 antibody reduced leukocytes infiltration into the cerebrospinal fluid and cytokine-induced BBB permeability (Del Maschio et al. 1999). A later study has gone

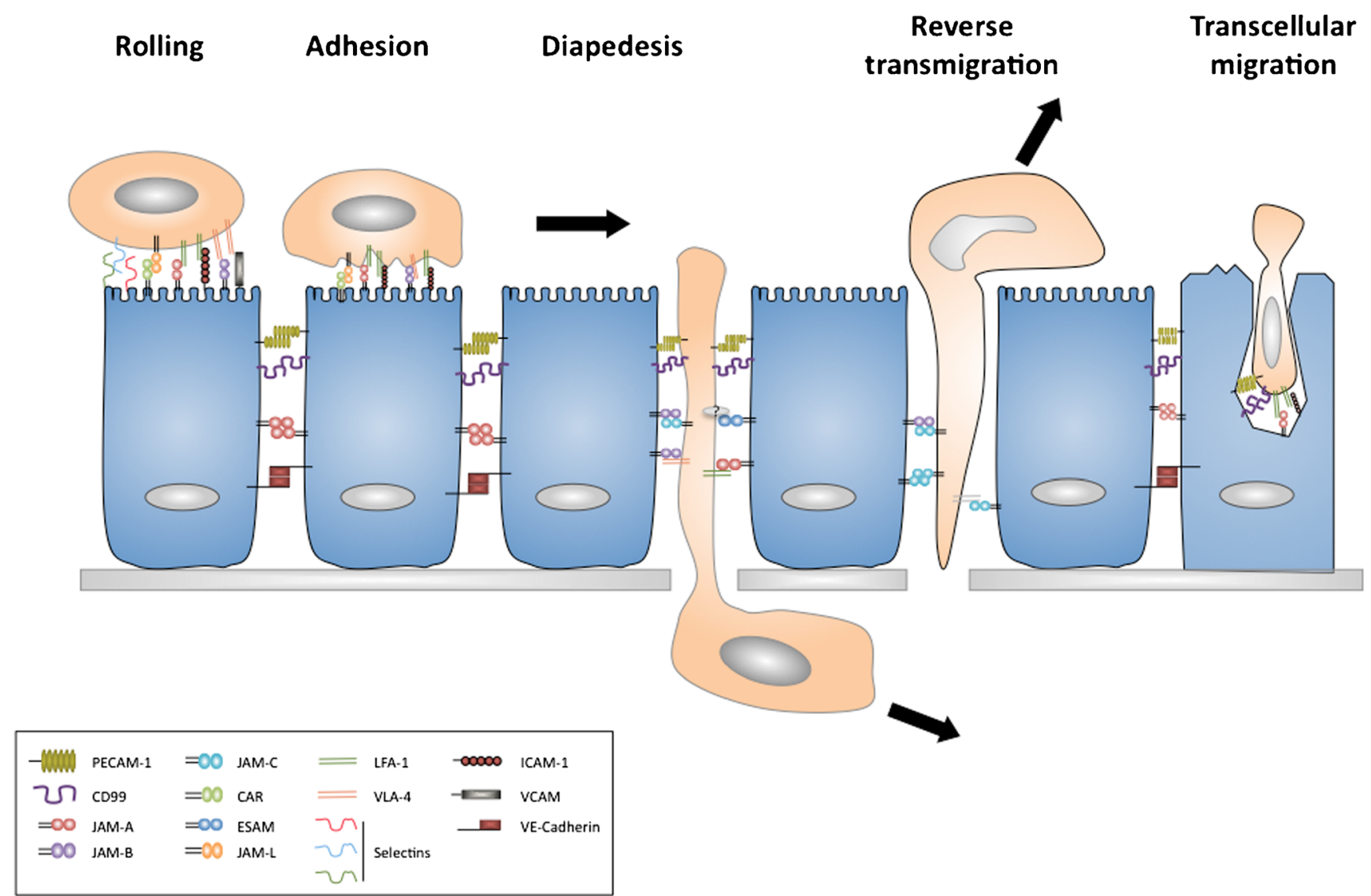

Fig. 4 Implication of JAMs in leukocyte transmigration. Migration of leukocytes across endothelium can be separated into distinct steps, rolling, adhesion, diapedesis and reverse transmigration. Under inflammatory conditions, JAMs are localized onto luminal surfaces of the endothelium and are able to interact with integrins on leukocyte surfaces. Along with PECAM-1 and CD99, JAM-A contributes to the migration of leukocytes in-between endothelial cells by diapedesis. In some cases where leukocytes cannot pass through the basal membrane, the leukocyte can exit the ablumenal compartment by reverse transmigration. This process is regulated by JAM-C. Leukocytes are able also to pass across the endothelium using a transcellular route. This process is regulated by CD99, PECAM-1, ICAM-1 and JAM-A 
further and shown that JAM-A controls leukocytes transendothelial migration through a direct interaction between LFA-1 (CD11a/CD18) and the C2 domain of JAM-A (Ostermann et al. 2002). In this study, it was observed that endothelial cells stimulated with PMA or the chemokine CXCL12 led to a reduction of T-lymphocyte and monocyte arrest on the endothelial layer in the presence of JAM-A blocking antibodies (Ostermann et al. 2002). The heterophilic interaction between JAM-A and LFA-1 has a higher affinity than homophilic JAM-A/JAM-A interaction (Ostermann et al. 2002). It has been proposed that, under resting conditions, JAM-A engages in homophilic interactions at cell-cell contacts but upon inflammation JAM-A relocalizes to the apical cell membrane where it can then interact with LFA-1 of neutrophils (Ostermann et al. 2002). This mechanism may promote the recruitment of leukocytes across the vascular barrier by enhancing cell adhesion events at the endothelial surface (Ozaki et al. 1999). However, not all studies are consistent with this finding, as several other anti-JAM-A antibodies are unable to block leukocyte transmigration (Lechner et al. 2000; Liu et al. 2000). Furthermore, the stimulation of endothelium with inflammatory cytokines has been shown to have no effect on JAM-A-dependent leukocyte transmigration under flow conditions (Shaw et al. 2001).

Other results obtained with JAM-A-deficient mice support these in vitro data where neutrophils trans-endothelial migration was reduced (Cera et al. 2004). In a model of acute lung injury, migration of neutrophils to the alveolar space is reduced in JAM-A-deficient animals or in the presence of antiJAM-A antibodies (Cera et al. 2004). However, in another study, it was shown that blocking of JAM-A does not necessarily correlate with reduced lung injury (Lakshmi et al. 2012). Surprisingly, the migration of dendritic cells (DC) to lymph nodes was shown to increase in JAM-A-deficient mice. This was shown to be due to a promigratory phenotype of DCs lacking JAM-A and was associated with enhanced contact hypersensitivity (Cera et al. 2004). Consistent with these findings, another study also described an increased migration of JAM-A-deficient DCs and T-cells to tumor sites (Murakami et al. 2010).

Intravital microscopy using mouse venules in cremaster muscle of different gene-deficient animal strains, has demonstrated a sequential action of ICAM-2, JAM-A and PECAM-1 during transendothelial migration of neutrophils after IL-1 stimulation (Woodfin et al. 2009). Intriguingly, when inflammation was stimulated by $\mathrm{TNF}-\alpha$, these molecules are not required for leukocyte transmigration (Woodfin et al. 2009). Further experiments confirmed a differential effect and usage of molecular mechanisms by transendothelial migrating neutrophils. Specifically, a reduction in migration was observed in JAM-A-deficient mice (or in the presence of an anti-JAM-A (BV11) antibody) when a tissue compartment was stimulated with IL-1, or in ischemia and reperfusion models but this was not the case after stimulation by leukotriene or PAF (Woodfin et al. 2007). This is consistent with the redistribution of JAMA being dependent on the type of stimuli and is supported by observations where JAM-A is redistributed with TNF- $\alpha$ stimulation but not with phorbol ester (Shaw et al. 2004). A more recent study has shown a role for endothelial JAM-A in monocyte recruitment into atherosclerotic plaques, using endothelium-specific JAM-A-deficient mice bred with ApoE-deficient mice (Schmitt et al. 2013). The endotheliumspecific JAM-A deficiency led to reduced monocyte migration through the arterial wall, which contrasted with leukocyte-specific JAM-A deficiency, which exhibited increased vascular permeability and lesion formation.

Apart from the role of JAM-A in paracellular transmigration of leukocytes, it has also been implicated in regulating the transcellular migratory route through an endothelial cell. In an in vitro study with HUVEC cells, it has been shown that JAM$\mathrm{A}$ is part of a molecular complex that surrounds the leukocyte (neutrophils or monocytes) migrating through the membrane channel formed by the endothelial cells, together with CD31 and CD99 (Mamdouh et al. 2009). This role appears not to be essential, as JAM-A blockade does not affect this process, which is in contrast to CD31 and CD99 (Mamdouh et al. 2009).

\section{JAM-B}

As discussed, vascular JAM-B interacts with JAM-C and the integrin $\alpha 4 \beta 1$. This integrin has previously been described as mediating memory T-lymphocyte adhesion to inflamed endothelium through VCAM-1 (Butcher and Picker 1996). At present, it is not clear whether the integrin can simultaneously engage VCAM-1 and JAM-B through different binding sites. However, it is also possible that JAM-B and VCAM1 may interact laterally and obtain integrin reinforcement by conformational changes. This may explain why JAM-B/ $\alpha 4 \beta 1$ interactions require JAM-B to engage with JAM-C in cis prior to this interaction (Cunningham et al. 2002). Other recent studies have proposed an independent role of JAM-B in leukocyte transmigration. Ludwig et al. (2005) demonstrated that anti-JAM-B and anti-JAM-C antibodies had an additive effect on blocking leukocytes infiltration in a model of allergic contact dermatitis. In a later study using a model of DNFBinduced contact hypersensitivity, JAM-B was shown to have a role in rolling and firm adhesion of T-lymphocytes through an interaction with $\alpha 4 \beta 1$ (Ludwig et al. 2009).

\section{JAM-C}

As mentioned previously, JAM-C is expressed on endothelial cells and human lymphocytes and can play a role in regulating leukocyte transmigration. The first study supporting this hypothesis came by enforced expression of JAM-C on endothelioma cell lines. These cells could support increased rates of 
leukocyte transmigration and this could be abrogated using anti-JAM-C antibodies (Johnson-Leger et al. 2002). This effect may be due to a homophilic interaction between multimers of JAM-C and JAM-B in trans or in cis formations (Santoso et al. 2002; (Arrate et al. 2001; Liang et al. 2002). Several other groups have implicated JAM-C in regulating leukocyte migration in different disease contexts. In rheumatoid arthritis patients and animal models, JAM-C overexpression has been observed in endothelial cells and has been proposed to play a role in leukocyte adhesion and retention within the inflamed synovium (Rabquer et al. 2008). In a diabetes-type I model (RIP-LCMV), JAM-C has been implicated in the recruitment of pathogenic T-lymphocytes into Langerhans islets (Christen et al. 2013). These transgenic mice expressing a protein of the lymphocytic choriomeningitis virus (LCMV) in $\beta$-cells, became diabetic after infection with LCMV virus. The authors found that, upon infection, JAM-C protein was upregulated near the islets. Moreover, JAM-C blockade with a neutralizing antiJAM-C antibody was able to reduce the incidence of type 1 diabetes. Similarly, in an ischemia and reperfusion model, JAM-C has been shown to regulate leukocyte transmigration (Scheiermann et al. 2009). In this study, they described that soluble JAM-C injected into mice as a pretreatment is able to inhibit leukocyte migration into zones of ischemia of the kidney and the cremaster muscle. Furthermore, leukocyte adhesion and transmigration, analyzed by intravital microscopy of the cremaster muscle model, was suppressed in JAM-Cdeficient mice and enhanced in mice overexpressing JAM-C specifically in the endothelium (Scheiermann et al. 2009).

However, a role for JAM-C beyond that of simple transmigration has been supported by a number of recent publications. A study in 2007 using blocking antibodies and JAM-C overexpression showed no effect of JAM-C on neutrophil transmigration across HUVECs (Sircar et al. 2007). This implies that the effect of JAM-C blockade on leukocyte trafficking in vivo may extend beyond that of the initial recruitment phase. This is supported by an extended in vitro study in which JAM-C has been shown to play a role in the reverse transmigration of monocytes, confirming that posttransmigratory events can be regulated by molecules such as JAM-C (Bradfield et al. 2007b). This process was first observed in vitro and has now been confirmed in vivo by 3D intravital microscopy (Woodfin et al. 2011). Both studies demonstrated that a proportion of transmigrated neutrophils or monocytes will reverse transmigrate back onto the luminal surfaces and return to the vascular compartment. In the study using monocytes, JAM-C-specific antibodies or JAM-C deficiency increased the number of leukocytes that reverse transmigrated (Bradfield et al. 2007b). This function may serve to block an overactive inflammatory response. However, this regulatory feedback loop may lead to reverse transmigrated cells, identified by high ICAM-1 expression, accumulating in the lungs where the secretion of reactive oxygen species can lead to the induction of lung edema (Woodfin et al. 2011). In conclusion, JAM-C promotes the unidirectional transmigration of leukocytes as disrupting this process by antibodies, or a reduction in gene expression, leads to increased reverse transmigration and a return to blood flow.

\section{Related JAMs}

In an intravital microscopy study performed on ESAMdeficient mice, neutrophil diapedesis was inhibited by $50 \%$ but the first steps of rolling and firm adhesion remained unaffected (Wegmann et al. 2006). It has been shown that ESAM is responsible for the maintenance of the tightness of endothelial junctions and VEGF-induced vascular permeability is affected by the absence of ESAM in knock-out animals (Wegmann et al. 2006). A recent study has shown that ESAM is also important for regulating monocyte migration during atherosclerosis (Inoue et al. 2010). As monocytes do not express ESAM, this result suggests that ESAM has another ligand that has yet to be elucidated.

The interaction of JAM-L/CAR is involved in regulating neutrophil, monocyte and T-cell transendothelial migration across the inflamed endothelium (Guo et al. 2009; Luissint et al. 2008; Zen et al. 2005). It has been shown that JAM-L is expressed by granulocytes and monocytes and is a ligand of CAR, which is present on the surface of endothelial cells (Guo et al. 2009; Luissint et al. 2008; Zen et al. 2005). However, JAM-L/CAR interactions can only be observed when leukocytes either do not express the integrin $\alpha 4 \beta 1$ or when this integrin is activated, otherwise JAM-L will form a complex with the non-activated integrin $\alpha 4 \beta 1$ at the surface of leukocytes.

\section{Concluding remarks}

The study of the JAM family has revealed these molecules as having functional duality: controlling the immune cell response through recruitment of leukocytes to sites of inflammation and regulating the formation of cellular junctions in epithelial and endothelial cells. Indeed, the JAMs participate in the transmigration of leukocytes from blood to inflamed tissue, by favoring the opening of the endothelial barrier for crossing leukocytes. JAM-C controls even one-way leukocyte traffic across the vascular barrier. At the same time, however, JAMs are important for the formation and the maintenance of endothelial junctions. Thus, there is clearly a dual role for these molecules. Nevertheless, many questions remain unanswered. For example, in the classical JAM family (JAM-A, -B and $-\mathrm{C}$ ), several extracellular ligands for each JAM have been identified, which is not the case for the non-classical JAM family members. The molecule CAR has only two 
ligands and ESAM and JAM-4 have only been confirmed in forming homophilic interactions.

Whilst the crystal structure of JAM-A has been fully elucidated, which revealed a bending site in the linker domain and a dimerization site in the $\mathrm{V}$ domain, this has not been confirmed for the other JAMs. The molecules JAM-B and -C present homology in these domains and a common mechanism of multimerization has been proposed. However, no study has as yet been conducted to confirm this binding process, even though JAM-B/-C heterodimerisation is known to take place.

Acknowledgments Our laboratory is supported by Swiss National Science Foundation grants (31003AB_135701) and ONCOSUISSE grants (KFS 2914-02-2012) to Prof B.A. Imhof.

\section{References}

Angelow S, Ahlstrom R, Yu AS (2008) Biology of claudins. Am J Physiol Ren Physiol 295:F867-F876

Arrate MP, Rodriguez JM, Tran TM, Brock TA, Cunningham SA (2001) Cloning of human junctional adhesion molecule 3 (JAM3) and its identification as the JAM2 counter-receptor. J Biol Chem 276: 45826-45832

Arthur FE, Shivers RR, Bowman PD (1987) Astrocyte-mediated induction of tight junctions in brain capillary endothelium: an efficient in vitro model. Brain Res 433:155-159

Asakura T, Nakanishi H, Sakisaka T, Takahashi K, Mandai K, Nishimura M, Sasaki T, Takai Y (1999) Similar and differential behaviour between the nectin-afadin-ponsin and cadherin-catenin systems during the formation and disruption of the polarized junctional alignment in epithelial cells. Genes Cells 4:573-581

Aurrand-Lions MA, Duncan L, Pasquier LD, Imhof BA (2000) Cloning of JAM-2 and JAM-3: an emerging junctional adhesion molecular family? Curr Top Microbiol Immunol 251:91-98

Aurrand-Lions M, Duncan L, Ballestrem C, Imhof BA (2001a) JAM-2, a novel immunoglobulin superfamily molecule, expressed by endothelial and lymphatic cells. J Biol Chem 276:2733-2741

Aurrand-Lions M, Johnson-Leger C, Wong C, Pasquier LD, Imhof BA (2001b) Heterogeneity of endothelial junctions is reflected by differential expression and specific subcellular localization of the three JAM family members. Blood 98:3699-3707

Barton ES, Forrest JC, Connolly JL, Chappell JD, Liu Y, Schnell FJ, Nusrat A, Parkos CA, Dermody TS (2001) Junction adhesion molecule is a receptor for reovirus. Cell 104:441-451

Bazzoni G, Dejana E (2004) Endothelial cell-to-cell junctions: molecular organization and role in vascular homeostasis. Physiol Rev 84:869-901

Bazzoni G, Martinez-Estrada OM, Mueller F, Nelboeck P, Schmid G, Bartfai T, Dejana E, Brockhaus M (2000) Homophilic interaction of junctional adhesion molecule. J Biol Chem 275:30970-30976

Bergelson JM, Cunningham JA, Droguett G, Kurt-Jones EA, Krithivas A, Hong JS, Horwitz MS, Crowell RL, Finberg RW (1997) Isolation of a common receptor for Coxsackie B viruses and adenoviruses 2 and 5. Science 275:1320-1323

Bradfield PF, Nourshargh S, Aurrand-Lions M, Imhof BA (2007a) JAM family and related proteins in leukocyte migration (Vestweber series). Arterioscler Thromb Vasc Biol 27:2104-2112

Bradfield PF, Scheiermann C, Nourshargh S, Ody C, Luscinskas FW, Rainger GE, Nash GB, Miljkovic-Licina M, Aurrand-Lions M,
Imhof BA (2007b) JAM-C regulates unidirectional monocyte transendothelial migration in inflammation. Blood 110:2545-2555

Brightman MW, Reese TS (1969) Junctions between intimately apposed cell membranes in the vertebrate brain. J Cell Biol 40:648-677

Butcher EC, Picker LJ (1996) Lymphocyte homing and homeostasis. Science 272:60-66

Cera MR, Del Prete A, Vecchi A, Corada M, Martin-Padura I, Motoike T, Tonetti P, Bazzoni G, Vermi W, Gentili F, Bernasconi S, Sato TN, Mantovani A, Dejana E (2004) Increased DC trafficking to lymph nodes and contact hypersensitivity in junctional adhesion moleculeA-deficient mice. J Clin Invest 114:729-738

Chretien I, Marcuz A, Courtet M, Katevuo K, Vainio O, Heath JK, White SJ, Pasquier LD (1998) CTX, a Xenopus thymocyte receptor, defines a molecular family conserved throughout vertebrates. Eur J Immunol 28:4094-4104

Christen S, Coppieters K, Rose K, Holdener M, Bayer M, Pfeilschifter JM, Hintermann E, von Herrath MG, Aurrand-Lions M, Imhof BA, Christen U (2013) Blockade but not overexpression of the junctional adhesion molecule $\mathrm{C}$ influences virus-induced type 1 diabetes in mice. PLoS ONE 8:e54675

Claude P (1978) Morphological factors influencing transepithelial permeability: a model for the resistance of the zonula occludens. J Membr Biol 39:219-232

Claude P, Goodenough DA (1973) Fracture faces of zonulae occludentes from "tight" and "leaky" epithelia. J Cell Biol 58:390-400

Cohen CJ, Shieh JT, Pickles RJ, Okegawa T, Hsieh JT, Bergelson JM (2001) The coxsackievirus and adenovirus receptor is a transmembrane component of the tight junction. Proc Natl Acad Sci U S A 98: 15191-15196

Coyne CB, Voelker T, Pichla SL, Bergelson JM (2004) The coxsackievirus and adenovirus receptor interacts with the multiPDZ domain protein-1 (MUPP-1) within the tight junction. J Biol Chem 279:48079-48084

Cunningham SA, Arrate MP, Rodriguez JM, Bjercke RJ, Vanderslice P, Morris AP, Brock TA (2000) A novel protein with homology to the junctional adhesion molecule. Characterization of leukocyte interactions. J Biol Chem 275:34750-34756

Cunningham SA, Rodriguez JM, Arrate MP, Tran TM, Brock TA (2002) JAM2 interacts with alpha4beta1. Facilitation by JAM3. J Biol Chem 277:27589-27592

Del Maschio A, De Luigi A, Martin-Padura I, Brockhaus M, Bartfai T, Fruscella P, Adorini L, Martino G, Furlan R, De Simoni MG, Dejana E (1999) Leukocyte recruitment in the cerebrospinal fluid of mice with experimental meningitis is inhibited by an antibody to junctional adhesion molecule (JAM). J Exp Med 190:1351-1356

Du Pasquier L, Courtet M, Chretien I (1999) Duplication and MHC linkage of the CTX family of genes in Xenopus and in mammals. Eur J Immunol 29:1729-1739

Ebnet K, Schulz CU, Meyer Zu Brickwedde MK, Pendl GG, Vestweber D (2000) Junctional adhesion molecule interacts with the PDZ domain-containing proteins AF-6 and ZO-1. J Biol Chem 275: 27979-27988

Ebnet K, Suzuki A, Horikoshi Y, Hirose T, Meyer Zu Brickwedde MK, Ohno S, Vestweber D (2001) The cell polarity protein ASIP/PAR-3 directly associates with junctional adhesion molecule (JAM). EMBO J 20:3738-3748

Ebnet K, Aurrand-Lions M, Kuhn A, Kiefer F, Butz S, Zander K, Meyer zu Brickwedde MK, Suzuki A, Imhof BA, Vestweber D (2003) The junctional adhesion molecule (JAM) family members JAM-2 and JAM-3 associate with the cell polarity protein PAR-3: a possible role for JAMs in endothelial cell polarity. J Cell Sci 116:3879-3891

Engelhardt B, Ransohoff RM (2012) Capture, crawl, cross: the T cell code to breach the blood-brain barriers. Trends Immunol 33:579 589

Excoffon KJ, Hruska-Hageman A, Klotz M, Traver GL, Zabner J (2004) A role for the PDZ-binding domain of the coxsackie B virus and 
adenovirus receptor (CAR) in cell adhesion and growth. J Cell Sci 117:4401-4409

Fanning AS, Jameson BJ, Jesaitis LA, Anderson JM (1998) The tight junction protein $\mathrm{ZO}-1$ establishes a link between the transmembrane protein occludin and the actin cytoskeleton. J Biol Chem 273: 29745-29753

Farquhar MG, Palade GE (1963) Junctional complexes in various epithelia. J Cell Biol 17:375-412

Fechner H, Haack A, Wang H, Wang X, Eizema K, Pauschinger M, Schoemaker R, Veghel R, Houtsmuller A, Schultheiss HP, Lamers J, Poller W (1999) Expression of coxsackie adenovirus receptor and alphav-integrin does not correlate with adenovector targeting in vivo indicating anatomical vector barriers. Gene Ther 6:1520-1535

Fukuhara A, Irie K, Yamada A, Katata T, Honda T, Shimizu K, Nakanishi $\mathrm{H}$, Takai Y (2002) Role of nectin in organization of tight junctions in epithelial cells. Genes Cells 7:1059-1072

Furuse M, Tsukita S (2006) Claudins in occluding junctions of humans and flies. Trends Cell Biol 16:181-188

Furuse M, Sasaki H, Fujimoto K, Tsukita S (1998) A single gene product, claudin-1 or -2 , reconstitutes tight junction strands and recruits occludin in fibroblasts. J Cell Biol 143:391-401

Gao L, Macara IG, Joberty G (2002) Multiple splice variants of Par3 and of a novel related gene, Par3L, produce proteins with different binding properties. Gene 294:99-107

Garrido-Urbani S, Bradfield PF, Lee BP, Imhof BA (2008) Vascular and epithelial junctions: a barrier for leucocyte migration. Biochem Soc Trans 36:203-211

Gliki G, Ebnet K, Aurrand-Lions M, Imhof BA, Adams RH (2004) Spermatid differentiation requires the assembly of a cell polarity complex downstream of junctional adhesion molecule-C. Nature 431:320-324

Guillemot L, Paschoud S, Pulimeno P, Foglia A, Citi S (2008) The cytoplasmic plaque of tight junctions: a scaffolding and signalling center. Biochim Biophys Acta 1778:601-613

Guo YL, Bai R, Chen CX, Liu DQ, Liu Y, Zhang CY, Zen K (2009) Role of junctional adhesion molecule-like protein in mediating monocyte transendothelial migration. Arterioscler Thromb Vasc Biol 29:75-83

Hamazaki Y, Itoh M, Sasaki H, Furuse M, Tsukita S (2002) Multi-PDZ domain protein 1 (MUPP1) is concentrated at tight junctions through its possible interaction with claudin-1 and junctional adhesion molecule. J Biol Chem 277:455-461

Hirabayashi S, Tajima M, Yao I, Nishimura W, Mori H, Hata Y (2003) JAM4, a junctional cell adhesion molecule interacting with a tight junction protein, MAGI-1. Mol Cell Biol 23:4267-4282

Hirata K, Ishida T, Penta K, Rezaee M, Yang E, Wohlgemuth J, Quertermous T (2001) Cloning of an immunoglobulin family adhesion molecule selectively expressed by endothelial cells. J Biol Chem 276:16223-16231

Iden S, Misselwitz S, Peddibhotla SS, Tuncay H, Rehder D, Gerke V, Robenek H, Suzuki A, Ebnet K (2012) aPKC phosphorylates JAMA at Ser285 to promote cell contact maturation and tight junction formation. J Cell Biol 196:623-639

Inoue M, Ishida T, Yasuda T, Toh R, Hara T, Cangara HM, Rikitake Y, Taira K, Sun L, Kundu RK, Quertermous T, Hirata K (2010) Endothelial cell-selective adhesion molecule modulates atherosclerosis through plaque angiogenesis and monocyte-endothelial interaction. Microvasc Res 80:179-187

Itoh M, Sasaki H, Furuse M, Ozaki H, Kita T, Tsukita S (2001) Junctional adhesion molecule (JAM) binds to PAR-3: a possible mechanism for the recruitment of PAR-3 to tight junctions. J Cell Biol 154:491-497

Johnson-Leger C, Imhof BA (2003) Forging the endothelium during inflammation: pushing at a half-open door? Cell Tissue Res 314: 93-105

Johnson-Leger CA, Aurrand-Lions M, Beltraminelli N, Fasel N, Imhof BA (2002) Junctional adhesion molecule-2 (JAM-2) promotes lymphocyte transendothelial migration. Blood 100:2479-2486
Kansaku A, Hirabayashi S, Mori H, Fujiwara N, Kawata A, Ikeda M, Rokukawa C, Kurihara H, Hata Y (2006) Ligand-of-Numb protein $\mathrm{X}$ is an endocytic scaffold for junctional adhesion molecule 4 . Oncogene 25:5071-5084

Keiper T, Al-Fakhri N, Chavakis E, Athanasopoulos AN, Isermann B, Herzog S, Saffrich R, Hersemeyer K, Bohle RM, Haendeler J, Preissner KT, Santoso S, Chavakis T (2005) The role of junctional adhesion molecule-C (JAM-C) in oxidized LDL-mediated leukocyte recruitment. FASEB J 19:2078-2080

Khounlotham M, Kim W, Peatman E, Nava P, Medina-Contreras O, Addis C, Koch S, Fournier B, Nusrat A, Denning TL, Parkos CA (2012) Compromised intestinal epithelial barrier induces adaptive immune compensation that protects from colitis. Immunity 37:563-573

Koenen RR, Pruessmeyer J, Soehnlein O, Fraemohs L, Zernecke A, Schwarz N, Reiss K, Sarabi A, Lindbom L, Hackeng TM, Weber C, Ludwig A (2009) Regulated release and functional modulation of junctional adhesion molecule A by disintegrin metalloproteinases. Blood 113:4799-4809

Kostrewa D, Brockhaus M, D'Arcy A, Dale GE, Nelboeck P, Schmid G, Mueller F, Bazzoni G, Dejana E, Bartfai T, Winkler FK, Hennig M (2001) X-ray structure of junctional adhesion molecule: structural basis for homophilic adhesion via a novel dimerization motif. EMBO J 20:4391-4398

Lakshmi SP, Reddy AT, Naik MU, Naik UP, Reddy RC (2012) Effects of JAM-A deficiency or blocking antibodies on neutrophil migration and lung injury in a murine model of ALI. Am J Physiol Lung Cell Mol Physiol 303:L758-L766

Lamagna C, Meda P, Mandicourt G, Brown J, Gilbert RJ, Jones EY, Kiefer F, Ruga P, Imhof BA, Aurrand-Lions M (2005) Dual interaction of JAM-C with JAM-B and alpha(M)beta2 integrin: function in junctional complexes and leukocyte adhesion. Mol Biol Cell 16: 4992-5003

Laukoetter MG, Nava P, Lee WY, Severson EA, Capaldo CT, Babbin BA, Williams IR, Koval M, Peatman E, Campbell JA, Dermody TS, Nusrat A, Parkos CA (2007) JAM-A regulates permeability and inflammation in the intestine in vivo. J Exp Med 204:3067-3076

Lechner F, Sahrbacher U, Suter T, Frei K, Brockhaus M, Koedel U, Fontana A (2000) Antibodies to the junctional adhesion molecule cause disruption of endothelial cells and do not prevent leukocyte influx into the meninges after viral or bacterial infection. J Infect Dis 182:978-982

Li X, Stankovic M, Lee BP, Aurrand-Lions M, Hahn CN, Lu Y, Imhof BA, Vadas MA, Gamble JR (2009) JAM-C induces endothelial cell permeability through its association and regulation of $\{$ beta 3 integrins. Arterioscler Thromb Vasc Biol 29:1200-1206

Liang TW, DeMarco RA, Mrsny RJ, Gurney A, Gray A, Hooley J, Aaron HL, Huang A, Klassen T, Tumas DB, Fong S (2000) Characterization of huJAM: evidence for involvement in cell-cell contact and tight junction regulation. Am J Physiol Cell Physiol 279: C1733-C1743

Liang TW, Chiu HH, Gurney A, Sidle A, Tumas DB, Schow P, Foster J, Klassen T, Dennis K, DeMarco RA, Pham T, Frantz G, Fong S (2002) Vascular endothelial-junctional adhesion molecule (VEJAM)/JAM 2 interacts with T, NK, and dendritic cells through JAM 3. J Immunol 168:1618-1626

Liu Y, Nusrat A, Schnell FJ, Reaves TA, Walsh S, Pochet M, Parkos CA (2000) Human junction adhesion molecule regulates tight junction resealing in epithelia. J Cell Sci 113(Pt 13):2363-2374

Ludwig RJ, Zollner TM, Santoso S, Hardt K, Gille J, Baatz H, Johann PS, Pfeffer J, Radeke HH, Schon MP, Kaufmann R, Boehncke WH, Podda M (2005) Junctional adhesion molecules (JAM)-B and -C contribute to leukocyte extravasation to the skin and mediate cutaneous inflammation. J Investig Dermatol 125:969-976

Ludwig RJ, Hardt K, Hatting M, Bistrian R, Diehl S, Radeke HH, Podda M, Schon MP, Kaufmann R, Henschler R, Pfeilschifter JM, Santoso S, Boehncke WH (2009) Junctional adhesion molecule (JAM)-B 
supports lymphocyte rolling and adhesion through interaction with alpha4betal integrin. Immunology 128:196-205

Luissint AC, Lutz PG, Calderwood DA, Couraud PO, Bourdoulous S (2008) JAM-L-mediated leukocyte adhesion to endothelial cells is regulated in cis by alpha4beta1 integrin activation. J Cell Biol 183: $1159-1173$

Mamdouh Z, Mikhailov A, Muller WA (2009) Transcellular migration of leukocytes is mediated by the endothelial lateral border recycling compartment. J Exp Med 206:2795-2808

Mandell KJ, Parkos CA (2005) The JAM family of proteins. Adv Drug Deliv Rev 57:857-867

Mandell KJ, Babbin BA, Nusrat A, Parkos CA (2005) Junctional adhesion molecule 1 regulates epithelial cell morphology through effects on beta1 integrins and Rap1 activity. J Biol Chem 280:11665-11674

Mandell KJ, Holley GP, Parkos CA, Edelhauser HF (2006) Antibody blockade of junctional adhesion molecule-A in rabbit corneal endothelial tight junctions produces corneal swelling. Investig Ophthalmol Vis Sci 47:2408-2416

Mandicourt G, Iden S, Ebnet K, Aurrand-Lions M, Imhof BA (2007) $\mathrm{JAM}-\mathrm{C}$ regulates tight junctions and integrin-mediated cell adhesion and migration. J Biol Chem 282:1830-1837

Mapoles JE, Krah DL, Crowell RL (1985) Purification of a HeLa cell receptor protein for group B coxsackieviruses. J Virol 55:560-566

Martinez-Estrada OM, Villa A, Breviario F, Orsenigo F, Dejana E, Bazzoni G (2001) Association of junctional adhesion molecule with calcium/calmodulin-dependent serine protein kinase (CASK/LIN-2) in human epithelial caco-2 cells. J Biol Chem 276:9291-9296

Martin-Padura I, Lostaglio S, Schneemann M, Williams L, Romano M, Fruscella P, Panzeri C, Stoppacciaro A, Ruco L, Villa A, Simmons D, Dejana E (1998) Junctional adhesion molecule, a novel member of the immunoglobulin superfamily that distributes at intercellular junctions and modulates monocyte transmigration. J Cell Biol 142: $117-127$

Mirza M, Hreinsson J, Strand ML, Hovatta O, Soder O, Philipson L, Pettersson RF, Sollerbrant K (2006) Coxsackievirus and adenovirus receptor (CAR) is expressed in male germ cells and forms a complex with the differentiation factor JAM-C in mouse testis. Exp Cell Res 312:817-830

Mitic LL, Anderson JM (1998) Molecular architecture of tight junctions. Annu Rev Physiol 60:121-142

Mochida GH, Ganesh VS, Felie JM, Gleason D, Hill RS, Clapham KR, Rakiec D, Tan WH, Akawi N, Al-Saffar M, Partlow JN, Tinschert S, Barkovich AJ, Ali B, Al-Gazali L, Walsh CA (2010) A homozygous mutation in the tight-junction protein JAM3 causes hemorrhagic destruction of the brain, subependymal calcification, and congenital cataracts. Am J Hum Genet 87:882-889

Monteiro AC, Sumagin R, Rankin CR, Leoni G, Mina MJ, Reiter DM, Stehle T, Dermody TS, Schaefer SA, Hall RA, Nusrat A, Parkos CA (2013) JAM-A associates with ZO-2, afadin, and PDZ-GEF1 to activate Rap2c and regulate epithelial barrier function. Mol Biol Cell 24:2849-2860

Moog-Lutz C, Cave-Riant F, Guibal FC, Breau MA, Di Gioia Y, Couraud PO, Cayre YE, Bourdoulous S, Lutz PG (2003) JAML, a novel protein with characteristics of a junctional adhesion molecule, is induced during differentiation of myeloid leukemia cells. Blood 102:3371-3378

Muller WA (2003) Leukocyte-endothelial-cell interactions in leukocyte transmigration and the inflammatory response. Trends Immunol 24: 327-334

Muller WA (2011) Mechanisms of leukocyte transendothelial migration. Annu Rev Pathol 6:323-344

Murakami M, Francavilla C, Torselli I, Corada M, Maddaluno L, Sica A, Matteoli G, Iliev ID, Mantovani A, Rescigno M, Cavallaro U, Dejana E (2010) Inactivation of junctional adhesion molecule-A enhances antitumoral immune response by promoting dendritic cell and T lymphocyte infiltration. Cancer Res 70:1759-1765
Nagai-Tamai Y, Mizuno K, Hirose T, Suzuki A, Ohno S (2002) Regulated protein-protein interaction between aPKC and PAR-3 plays an essential role in the polarization of epithelial cells. Genes Cells 7: 1161-1171

Nagamatsu G, Ohmura M, Mizukami T, Hamaguchi I, Hirabayashi S, Yoshida S, Hata Y, Suda T, Ohbo K (2006) A CTX family cell adhesion molecule, JAM4, is expressed in stem cell and progenitor cell populations of both male germ cell and hematopoietic cell lineages. Mol Cell Biol 26:8498-8506

Nagy Z, Peters H, Huttner I (1984) Fracture faces of cell junctions in cerebral endothelium during normal and hyperosmotic conditions. Lab Investig 50:313-322

Naik MU, Mousa SA, Parkos CA, Naik UP (2003) Signaling through JAM-1 and alphavbeta3 is required for the angiogenic action of bFGF: dissociation of the JAM-1 and alphavbeta3 complex. Blood 102:2108-2114

Nasdala I, Wolburg-Buchholz K, Wolburg H, Kuhn A, Ebnet K, Brachtendorf G, Samulowitz U, Kuster B, Engelhardt B, Vestweber D, Butz S (2002) A transmembrane tight junction protein selectively expressed on endothelial cells and platelets. J Biol Chem 277:16294-16303

Noutsias M, Fechner H, de Jonge H, Wang X, Dekkers D, Houtsmuller $\mathrm{AB}$, Pauschinger M, Bergelson J, Warraich R, Yacoub M, Hetzer R, Lamers J, Schultheiss HP, Poller W (2001) Human coxsackieadenovirus receptor is colocalized with integrins alpha(v)beta(3) and alpha(v)beta(5) on the cardiomyocyte sarcolemma and upregulated in dilated cardiomyopathy: implications for cardiotropic viral infections. Circulation 104:275-280

Orlova VV, Economopoulou M, Lupu F, Santoso S, Chavakis T (2006) Junctional adhesion molecule-C regulates vascular endothelial permeability by modulating VE-cadherin-mediated cell-cell contacts. J Exp Med 203:2703-2714

Ostermann G, Weber KS, Zernecke A, Schroder A, Weber C (2002) JAM-1 is a ligand of the beta(2) integrin LFA-1 involved in transendothelial migration of leukocytes. Nat Immunol 3:151-158

Ozaki H, Ishii K, Horiuchi H, Arai H, Kawamoto T, Okawa K, Iwamatsu A, Kita T (1999) Cutting edge: combined treatment of TNF-alpha and IFN-gamma causes redistribution of junctional adhesion molecule in human endothelial cells. J Immunol 163:553-557

Padden M, Leech S, Craig B, Kirk J, Brankin B, McQuaid S (2007) Differences in expression of junctional adhesion molecule-A and beta-catenin in multiple sclerosis brain tissue: increasing evidence for the role of tight junction pathology. Acta Neuropathol 113:177-186

Palmeri D, van Zante A, Huang CC, Hemmerich S, Rosen SD (2000) Vascular endothelial junction-associated molecule, a novel member of the immunoglobulin superfamily, is localized to intercellular boundaries of endothelial cells. J Biol Chem 275:19139-19145

Prota AE, Campbell JA, Schelling P, Forrest JC, Watson MJ, Peters TR, Aurrand-Lions M, Imhof BA, Dermody TS, Stehle T (2003) Crystal structure of human junctional adhesion molecule 1: implications for reovirus binding. Proc Natl Acad Sci USA 100:5366-5371

Rabquer BJ, Pakozdi A, Michel JE, Gujar BS, Haines GK 3rd, Imhof BA, Koch AE (2008) Junctional adhesion molecule $C$ mediates leukocyte adhesion to rheumatoid arthritis synovium. Arthritis Rheum 58: 3020-3029

Rabquer BJ, Amin MA, Teegala N, Shaheen MK, Tsou PS, Ruth JH, Lesch CA, Imhof BA, Koch AE (2010) Junctional adhesion molecule-C is a soluble mediator of angiogenesis. J Immunol 185:1777-1785

Reese TS, Karnovsky MJ (1967) Fine structural localization of a bloodbrain barrier to exogenous peroxidase. J Cell Biol 34:207-217

Rubin LL, Hall DE, Porter S, Barbu K, Cannon C, Horner HC, Janatpour M, Liaw CW, Manning K, Morales J et al (1991) A cell culture model of the blood-brain barrier. J Cell Biol 115:1725-1735

Saitou M, Furuse M, Sasaki H, Schulzke JD, Fromm M, Takano H, Noda T, Tsukita S (2000) Complex phenotype of mice lacking occludin, a component of tight junction strands. Mol Biol Cell 11:4131-4142 
Salifu MO, Kolff Q, Murty P, Haria DM, Zimpa M, Shakeel M, Lee H, Kornecki E, Babinska A (2007) Relationship between the soluble F11 receptor and markers of inflammation in hemodialysis patients. J Investig Med 55:115-119

Santoso S, Sachs UJ, Kroll H, Linder M, Ruf A, Preissner KT, Chavakis T (2002) The junctional adhesion molecule 3 (JAM-3) on human platelets is a counterreceptor for the leukocyte integrin Mac-1. J Exp Med 196:679-691

Scheiermann C, Colom B, Meda P, Patel NS, Voisin MB, Marrelli A, Woodfin A, Pitzalis C, Thiemermann C, Aurrand-Lions M, Imhof BA, Nourshargh S (2009) Junctional adhesion molecule-C mediates leukocyte infiltration in response to ischemia reperfusion injury. Arterioscler Thromb Vasc Biol 29:1509-1515

Schmitt MM, Megens RT, Zernecke A, Bidzhekov K, van den Akker NM, Rademakers T, van Zandvoort MA, Hackeng TM, Koenen RR, Weber C (2013) Endothelial JAM-A guides monocytes into flowdependent predilection sites of atherosclerosis. Circulation 24(4): 217-222

Shaw SK, Perkins BN, Lim YC, Liu Y, Nusrat A, Schnell FJ, Parkos CA, Luscinskas FW (2001) Reduced expression of junctional adhesion molecule and platelet/endothelial cell adhesion molecule-1 (CD31) at human vascular endothelial junctions by cytokines tumor necrosis factor-alpha plus interferon-gamma Does not reduce leukocyte transmigration under flow. Am J Pathol 159:2281-2291

Shaw SK, Ma S, Kim MB, Rao RM, Hartman CU, Froio RM, Yang L, Jones T, Liu Y, Nusrat A, Parkos CA, Luscinskas FW (2004) Coordinated redistribution of leukocyte LFA-1 and endothelial cell ICAM-1 accompany neutrophil transmigration. J Exp Med 200: $1571-1580$

Sircar M, Bradfield PF, Aurrand-Lions M, Fish RJ, Alcaide P, Yang L, Newton G, Lamont D, Sehrawat S, Mayadas T, Liang TW, Parkos CA, Imhof BA, Luscinskas FW (2007) Neutrophil transmigration under shear flow conditions in vitro is junctional adhesion moleculeC independent. J Immunol 178:5879-5887

Sobocka MB, Sobocki T, Banerjee P, Weiss C, Rushbrook JI, Norin AJ, Hartwig J, Salifu MO, Markell MS, Babinska A, Ehrlich YH, Kornecki E (2000) Cloning of the human platelet F11 receptor: a cell adhesion molecule member of the immunoglobulin superfamily involved in platelet aggregation. Blood 95:2600-2609

Sollerbrant K, Raschperger E, Mirza M, Engstrom U, Philipson L, Ljungdahl PO, Pettersson RF (2003) The Coxsackievirus and adenovirus receptor (CAR) forms a complex with the PDZ domaincontaining protein ligand-of-numb protein-X (LNX). J Biol Chem 278:7439-7444

Stalker TJ, Wu J, Morgans A, Traxler EA, Wang L, Chatterjee MS, Lee D, Quertermous T, Hall RA, Hammer DA, Diamond SL, Brass LF (2009) Endothelial cell specific adhesion molecule (ESAM) localizes to platelet-platelet contacts and regulates thrombus formation in vivo. J Thromb Haemost 7:1886-1896

Suzuki A, Ohno S (2006) The PAR-aPKC system: lessons in polarity. J Cell Sci 119:979-987

Suzuki A, Yamanaka T, Hirose T, Manabe N, Mizuno K, Shimizu M, Akimoto K, Izumi Y, Ohnishi T, Ohno S (2001) Atypical protein kinase $\mathrm{C}$ is involved in the evolutionarily conserved par protein complex and plays a critical role in establishing epithelia-specific junctional structures. J Cell Biol 152:1183-1196

Suzuki A, Ishiyama C, Hashiba K, Shimizu M, Ebnet K, Ohno S (2002) aPKC kinase activity is required for the asymmetric differentiation of the premature junctional complex during epithelial cell polarization. J Cell Sci 115:3565-3573

Tao-Cheng JH, Nagy Z, Brightman MW (1987) Tight junctions of brain endothelium in vitro are enhanced by astroglia. J Neurosci 7:32933299

Tomko RP, Johansson CB, Totrov M, Abagyan R, Frisen J, Philipson L (2000) Expression of the adenovirus receptor and its interaction with the fiber knob. Exp Cell Res 255:47-55
Tsukita S, Furuse M, Itoh M (2001) Multifunctional strands in tight junctions. Nat Rev Mol Cell Biol 2:285-293

Van Itallie CM, Anderson JM (2006) Claudins and epithelial paracellular transport. Annu Rev Physiol 68:403-429

Vorbrodt AW, Dobrogowska DH (2004) Molecular anatomy of interendothelial junctions in human blood-brain barrier microvessels. Folia Histochem Cytobiol 42:67-75

Wegmann F, Ebnet K, Pasquier LD, Vestweber D, Butz S (2004) Endothelial adhesion molecule ESAM binds directly to the multidomain adaptor MAGI-1 and recruits it to cell contacts. Exp Cell Res 300:121-133

Wegmann F, Petri B, Khandoga AG, Moser C, Khandoga A, Volkery S, Li H, Nasdala I, Brandau O, Fassler R, Butz S, Krombach F, Vestweber D (2006) ESAM supports neutrophil extravasation, activation of Rho, and VEGF-induced vascular permeability. J Exp Med 203:1671-1677

Williams AF, Barclay AN (1988) The immunoglobulin superfamilydomains for cell surface recognition. Annu Rev Immunol 6:381405

Williams DW, Calderon TM, Lopez L, Carvallo-Torres L, Gaskill PJ, Eugenin EA, Morgello S, Berman JW (2013) Mechanisms of HIV Entry into the CNS: increased sensitivity of HIV infected CD14(+ )CD16(+) monocytes to CCL2 and key roles of CCR2, JAM-A, and ALCAM in diapedesis. PLoS ONE 8:e69270

Wolburg H, Lippoldt A (2002) Tight junctions of the blood-brain barrier: development, composition and regulation. Vasc Pharmacol 38:323337

Wolburg H, Neuhaus J, Kniesel U, Krauss B, Schmid EM, Ocalan M, Farrell C, Risau W (1994) Modulation of tight junction structure in blood-brain barrier endothelial cells. Effects of tissue culture, second messengers and cocultured astrocytes. J Cell Sci 107(Pt 5): $1347-1357$

Wong AD, Ye M, Levy AF, Rothstein JD, Bergles DE, Searson PC (2013) The blood-brain barrier: an engineering perspective. Front Neuroenerg 6:7

Woodfin A, Reichel CA, Khandoga A, Corada M, Voisin MB, Scheiermann C, Haskard DO, Dejana E, Krombach F, Nourshargh S (2007) JAM-A mediates neutrophil transmigration in a stimulusspecific manner in vivo: evidence for sequential roles for JAM-A and PECAM-1 in neutrophil transmigration. Blood 110:1848-1856

Woodfin A, Voisin MB, Imhof BA, Dejana E, Engelhardt B, Nourshargh S (2009) Endothelial cell activation leads to neutrophil transmigration as supported by the sequential roles of ICAM-2, JAM-A, and PECAM-1. Blood 113:6246-6257

Woodfin A, Voisin MB, Beyrau M, Colom B, Caille D, Diapouli FM, Nash GB, Chavakis T, Albelda SM, Rainger GE, Meda P, Imhof BA, Nourshargh S (2011) The junctional adhesion molecule JAM-C regulates polarized transendothelial migration of neutrophils in vivo. Nat Immunol 12:761-769

Wyss L, Schafer J, Liebner S, Mittelbronn M, Deutsch U, Enzmann G, Adams RH, Aurrand-Lions M, Plate KH, Imhof BA, Engelhardt B (2012) Junctional adhesion molecule (JAM)-C deficient C57BL/6 mice develop a severe hydrocephalus. PLoS ONE 7:e45619

Yamanaka T, Horikoshi Y, Suzuki A, Sugiyama Y, Kitamura K, Maniwa R, Nagai Y, Yamashita A, Hirose T, Ishikawa H, Ohno S (2001) PAR-6 regulates aPKC activity in a novel way and mediates cell-cell contact-induced formation of the epithelial junctional complex. Genes Cells 6:721-731

Yeung D, Manias JL, Stewart DJ, Nag S (2008) Decreased junctional adhesion molecule-A expression during blood-brain barrier breakdown. Acta Neuropathol 115:635-642

Zen K, Liu Y, McCall IC, Wu T, Lee W, Babbin BA, Nusrat A, Parkos CA (2005) Neutrophil migration across tight junctions is mediated by adhesive interactions between epithelial coxsackie and adenovirus receptor and a junctional adhesion molecule-like protein on neutrophils. Mol Biol Cell 16:2694-2703 